\title{
Educação escolar no campo: desafios à educação especial
}

\author{
Katia Regina Moreno Caiado \\ Universidade Federal de São Carlos \\ Taísa Grasiela Gomes Liduenha Gonçalves \\ Universidade Norte do Paraná \\ Michele Aparecida de Sá \\ Centro Universitário Metodista Izabela Hendrix
}

\section{Resumo}

Historicamente, há um silenciamento educacional sobre as pessoas com deficiência que vivem no campo. Desse modo, o objetivo deste estudo foi analisar a educação especial no campo por meio da legislação, de indicadores sociais e dos relatórios do Programa de Benefício de Prestação Continuada (BPC na Escola). Os resultados revelam que houve uma ampliação das matrículas de alunos com necessidades educacionais especiais que vivem no campo, mas que precisam se deslocar até a cidade para a escolarização. Além disso, aumentou o acesso à escola por parte dos beneficiários do Programa BPC na Escola, porém ainda há 31,58\% dos beneficiários fora da escola.

Palavras-chave: Educação Especial. Educação do Campo. Desigualdade Social. Direitos Humanos. 


\section{Countryside education: challenges to the special education}

Historically, there is an educational silencing of people with disabilities living in rural areas. Thus, the aim of this study was analyze special education at the countryside through legislation, the social indicators and the reports of the Program of Benefit of Continuing Provision - BPC in school. The results reveal that there has been an expansion in enrolment of students with special needs living in the countryside, however they need to move to the city for schooling; there has been an increase in enrolment by BPC beneficiaries, although there is still $31,58 \%$ of these out of school.

Keywords: Special Education. Countryside Education. Social Inequality. Human Rights.

\section{Escolarización en el campo: desafío para la educación especial}

Históricamente, hay un silenciamiento educativa de las personas con discapacidad que viven en las zonas rurales. Con eso, el objetivo de este trabajo fue analizar la educación especial en el campo a través de la legislación, de los indicadores sociales y de los informes del Programa de Beneficio de Prestación Continua - BPC en la escuela. Los resultados revelan que hubo una ampliación de las inscripciones de alumnos con necesidades educativas especiales que viven en el campo, sin embargo, ellos necesitan transporte hasta la ciudad para llegar a la escuela; aumentó la cantidad de los beneficiarios en la escuela, pero todavía hay $31,58 \%$ de ellos fuera de la escuela.

Palabras-clave: Educación Especial. Educación del Campo. Desigualdad Social. Derechos Humanos. 


\section{Introdução}

A dívida histórica que o Estado brasileiro tem com a educação persiste em diferentes áreas e dimensões, como nos índices de analfabetismo, na desvalorização do trabalho docente, na privatização da educação, no abandono das escolas do campo, na condição da educação especial enquanto área de filantropia e não de direito.

Instigadas a analisar os direitos das pessoas com deficiência ${ }^{1}$ em nosso país, logo nos deparamos com a invisibilidade que há sobre a interface entre a educação especial e a educação do campo. Poucos e recentes são os estudos nessa área (Caiado; Meletti, 2011; Bruno, 2009²; Oliveira et al., 2011).

No entanto, dados de realidade nos mostram que há pessoas com deficiência que vivem no campo e há alunos com deficiência que vivem no campo e estão matriculados em escolas das áreas rural ou urbana. Há crianças e jovens com deficiência que vivem em terras indígenas, comunidades remanescentes de quilombos, assentamentos, comunidades ribeirinhas e demais áreas rurais em nosso país (IBGE, 2010; Brasil, 2012a).

Pouco se fala sobre esse tema. Recentemente, a legislação tem destacado que as ações na área da educação especial devem considerar as áreas rurais, bem como a educação do campo, de indígenas e quilombolas, e garantir a interface com a educação especial.

A Resolução $n^{\circ}$ 2/2008 (Brasil, 2008a), por exemplo, específica da educação do campo, afirma que:

$\S 5^{\circ}$ - Os sistemas de ensino adotarão providências para que as crianças e os jovens portadores de necessidades especiais, objeto da modalidade de Educação Especial, residentes no campo, também tenham acesso à Educação Básica, preferentemente em escolas comuns da rede de ensino regular.

Outro documento a ser destacado é a Política Nacional de Educação Especial na Perspectiva da Educação Inclusiva, no qual se afirma:

3 Segundo o Decreto 6.949 (Brasil, 2009b, p.26) pessoas com deficiência são "aquelas que têm impedimentos de longo prazo de natureza física, mental, intelectual ou sensorial, os quais, em interação com diversas barreiras, podem obstruir sua participação plena e efetiva na sociedade em igualdades de condições com as demais pessoas".

4 Projeto de pesquisa intitulado "Mapeamento de deficiências na população indígena da Região da Grande Dourados, MS: um estudo sobre os impactos e as possíveis implicações para a inclusão educacional", desenvolvido com apoio do PROESP/CAPES. 
A interface da educação especial na educação indígena, do campo e quilombola deve assegurar que os recursos, serviços e atendimento educacional especializado estejam presentes nos projetos pedagógicos construídos com base nas diferenças socioculturais desses grupos. (Brasil, 2008b, p. 17)

Recentemente, o Plano Nacional de Educação (PNE), aprovado na Lei n 13.005 (Brasil, 2014a), trata da educação especial ao anunciar a meta: "universalizar, para a população de 4 a 17 anos, o atendimento escolar aos estudantes com deficiência, transtornos globais do desenvolvimento e altas habilidades ou superdotação na rede regular de ensino" (Brasil, 2014a, p. 6). Além disso, apresenta a interface da educação especial com a educação do campo enquanto estratégia: "implantar, ao longo desse PNE, salas de recursos multifuncionais e fomentar a formação continuada de professores e professoras para o atendimento educacional especializado complementar, nas escolas urbanas e rurais" (Brasil, 2014a, p. 6, item 4.3).

Apesar de a interface estar garantida na legislação nacional, pouco se estuda sobre a vida de pessoas com deficiência que vivem em famílias de trabalhadores, seja no campo ou na cidade. Falar de inclusão como um fenômeno desvinculado das reais condições da vida nos coloca a discutir sobre um fenômeno etéreo, a-histórico, que pouco ou nada contribui para a superação dos desafios trazidos pela vida.

O direito à escola compreende as dimensões de matrícula, permanência e vivência de um currículo escolar que possibilite a participação social, a formação humana. Em outros estudos, já anunciamos a presença de alunos com deficiência em escolas do campo (Caiado; Gonçalves, 2013; Sá, 2013). Dois motivos nos trazem novamente para essa discussão. Primeiro, apresentar uma análise referente às matrículas de alunos com deficiência na educação básica diferenciando as matrículas em escolas de área rural daquelas em escolas de assentamentos, terra indígena e áreas remanescentes de quilombos. Segundo, o aumento das matrículas de beneficiários da assistência social com deficiência, ocorrido com a criação do Programa Benefício de Prestação Continuada (BPC) na escola ${ }^{3}$. Esse novo quadro precisa ser estudado pelos pesquisadores e profissionais da educação especial para que possamos colaborar nos apoios necessários aos alunos, à escola, às famílias e aos professores.

$\mathrm{Na}$ tentativa de conhecer uma realidade concreta, apresentamos a análise das matrículas de alunos com deficiência que estudam em escolas do campo, com um destaque às matrículas em áreas de assentamentos, terras indígenas e áreas remanescentes de quilombos, assim como dos beneficiários com deficiência em escolas do campo.

${ }_{5}$ O Programa BPC na Escola será apresentado no texto. 


\section{A educação especial e a educação do campo: uma análise dos indicadores sociais}

Neste estudo, compreende-se a análise dos indicadores sociais em uma perspectiva materialista e crítica, em que as dimensões de qualidade e quantidade compõem uma unidade. Ferraro (2012, p. 144) afirma que nesta abordagem "não há quantidade sem qualidade, nem qualidade sem quantidade, a unidade entre essas duas dimensões do real está em sua inseparabilidade ou exigência recíproca, não em qualquer identidade imaginária entre ambas". Ainda, segundo o autor, esta perspectiva afasta-se de concepções que colocam quantidade e qualidade como opostas ou complementares.

A contraposição entre quantidade e qualidade é racionalmente um contrassenso que, segundo Gramsci (1981, p. 50), "mantém intactas determinadas condições de vida social, nas quais algumas são pura quantidade, outras pura qualidade". Ainda destaca,

[...] afirmar, portanto, que se quer trabalhar sobre a quantidade, que se quer desenvolver o aspecto "corpóreo" do real, não significa que se pretenda esquecer a "qualidade", mas, ao contrário, que se deseja colocar o problema qualitativo da maneira mais concreta e realista, isto é, deseja-se desenvolver a qualidade pelo único modo no qual tal desenvolvimento é controlável e mensurável.

Partindo deste enfoque, os dados que iremos apresentar foram selecionados das informações divulgadas pelo Instituto Nacional de Estudos e Pesquisas Educacional Anísio Teixeira (Inep), do Ministério da Educação (MEC), por meio dos Censos Escolares de 2008 a 2012, e pelo Instituto Brasileiro de Geografia e Estatística (IBGE), por meio do Censo Demográfico de 2010.

Sobre o período de análise do censo escolar, o ano inicial de 2008 foi delimitado por ter sido o posterior ao estabelecimento da Política Nacional de Educação Especial na Perspectiva da Educação Inclusiva (Brasil, 2008b), implantada pela Secretaria de Educação Especial, do Ministério da Educação, em 2008. O último ano analisado foi 2012, por ser a origem dos dados mais atuais do Censo Escolar da Educação Básica no momento do estudo (Brasil, 2012b).

No censo escolar, trabalhou-se com os dados de matrículas que foram agregados segundo as variáveis4: zona residencial do aluno (rural; urbana); localização da escola (rural; urbana); localização diferenciada da escola (área rural; área de assentamento; terra indígena; área remanescente de quilombo); necessidade educacional especial $(\mathrm{NEE})^{5}$.

As nomenclaturas das variáveis estão de acordo com o caderno de instruções do Inep, disponível no endereço eletrônico: <http://portal.inep.gov.br/basica-levantamentos-microdados>. Acesso em: 25 mar. 2013.

7 Estudantes com deficiência, transtornos globais do desenvolvimento ou altas habilidades/superdotação (Caderno de Instruções, Inep). 
Também foi analisado o último censo demográfico. As variáveis ${ }^{6}$ selecionadas no Sistema IBGE de Recuperação Automática (SIDRA) (IBGE, 2012) correspondem à totalidade da população a partir da situação do domicílio (rural; urbano) e do tipo de deficiência permanente (visual, auditiva, motora, mental ou intelectual), que apresenta uma das duas características: 'não consegue de modo algum' ou 'grande dificuldade'.

A Tabela 1 apresenta a população brasileira segundo a situação de domicílio e deficiência permanente.

Tabela 1: População brasileira segundo a situação de domicílio e deficiência

\begin{tabular}{llllllll}
\hline \multicolumn{2}{l}{ Total da população } & & \multicolumn{5}{l}{ Total da população com deficiência } \\
\hline Cidade & $\%$ & Campo & $\%$ & Cidade & $\%$ & Campo & $\%$ \\
\hline 160.934 .649 & 84,37 & 29.821 .150 & 15,63 & 13.186 .355 & 83,72 & 2.564 .614 & 16,28 \\
\hline
\end{tabular}

Fonte: Elaboração própria com base no censo demográfico do IBGE/SIDRA (2012).

O Censo Demográfico de 2010 (IBGE, 2010) mostra que somos 190.755 .799 brasileiros; desse total, $15,63 \%$ vivem no campo. Ao tratar das pessoas com deficiência permanente (visual, auditiva, motora, mental/intelectual), o IBGE (2010) aponta que no Brasil há um total de 15.750 .969 indivíduos, sendo que 16,28\% das pessoas com deficiência vivem no campo, correspondendo a 8,59\% da população total do campo.

Ainda de acordo com o IBGE (2010), no Brasil, 7,97\% das pessoas com deficiência permanente que vivem no campo encontram-se na faixa etária de 0 a 14 anos, ou seja, estão em idade escolar. Entende-se que podem estar matriculadas em creches, pré-escolas e no ensino fundamental ou, até mesmo, podem estar fora da escola.

Como forma de ilustrar melhor a realidade concreta vivenciada pelas pessoas que vivem no campo, apresentamos dados de matrículas na educação básica segundo a localização da escola (campo; cidade), conforme a Figura 1.

8 As nomenclaturas das variáveis estão de acordo com o SIDRA, disponíveis no endereço eletrônico: <http://www. sidra.ibge.gov.br>. Acesso em: 18 mar. 2013. 
Figura 1: Média das matrículas de alunos da educação básica segundo a localização da escola no período de 2008 a 2012

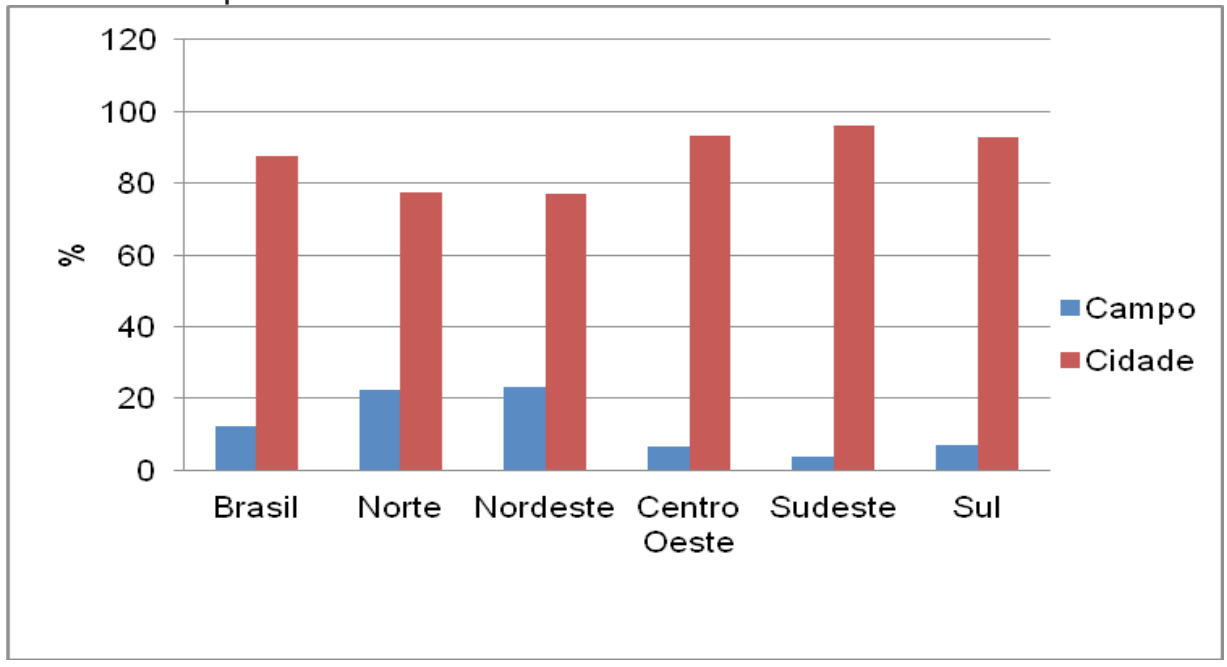

Fonte: Elaboração própria com base nos microdados do Inep (Brasil, 2008c; 2009a; 2010; 2011a; 2012 b).

Apesar das regiões Sudeste (3,90\%), Centro-Oeste (6,61\%) e Sul (7,22\%) apresentarem, em média, um número reduzido de matrículas no campo, as regiões Norte e Nordeste mostram outra realidade educacional em áreas rurais, com, respectivamente, $22,69 \%$ e $23,41 \%$ das matrículas concentradas em escolas do campo. De acordo com dados do IBGE (2010), na região Norte e Nordeste, respectivamente, $26,4 \%$ e $26,86 \%$ da população vive em áreas rurais, enquanto nas regiões Sudeste (7,5\%), Centro-Oeste $(11,2 \%)$ e Sul $(15,06 \%)$ o número de pessoas que vivem no campo é inferior.

Conforme Romanelli (1998, p. 62), em 1920, 84\% da população brasileira vivia em área rural, e o índice de analfabetismo no país era de 70\%. Em 1964, 74\% das pessoas entre 7 e 14 anos que viviam em zona rural não frequentavam a escola. Em 1970, 44\% da população brasileira permanecia morando em área rural e o índice de analfabetismo no país era de $33 \%$. Com o decorrer do processo de industrialização no país, houve um movimento crescente de migração do campo para a cidade, formando-se bolsões urbanos de miséria.

Dados do Instituto Nacional de Colonização e Reforma Agrária (INCRA), em 2010, mostram que grandes latifúndios detêm $75 \%$ da área rural do país, o que revela a manutenção histórica da concentração da terra. Dados do Censo (IBGE, 2010) mostram que $72,1 \%$ da população do campo com 15 anos ou mais são analfabetas ou possuem o nível fundamental incompleto.

No Brasil, as matrículas em escolas do campo correspondem, em média, a 12,38\% das 
matrículas da educação básica. Esses índices desvelam as políticas de fechamento das escolas do campo por ação de vários governos, nas três esferas. Pinto (2012, p. 376) afirma que entre 1977 e 2009 "foram fechadas 65 mil escolas rurais somente no ensino fundamental, uma redução de 46\%". Vários autores (Vendramini, 2007; Hage, 2011; Munarim, 2011) apontam que transportar os alunos do campo às escolas da cidade é menos custoso ao cofre público do que manter pequenas escolas em áreas rurais. Diante desse contexto, o Movimento dos Trabalhadores Rurais Sem Terra fez intensa luta contra o fechamento de escolas do campo, com a Campanha: Fechar Escola é Crime! Após grande mobilização, a Lei n 12.960 (Brasil, 2014b), de 27 março de 2014, em parágrafo único, assegura o fechamento de escolas do campo, indígenas e quilombolas precedido de manifestação do órgão normativo do respectivo sistema de ensino, que considerará a justificativa apresentada pela Secretaria de Educação, a análise do diagnóstico do impacto da ação e a manifestação da comunidade escolar.

Toda a nossa análise, portanto, precisa considerar o número significativo de alunos que vivem no campo e estudam na cidade, inclusive alunos com NEE (conforme a terminologia utilizada pelo INEP no Censo Escolar). Em estudo anterior, Caiado e Meletti (2011) analisaram os dados de matrículas do censo escolar no período de 2007 a 2010 e apontaram que as matrículas de alunos que vivem e estudam no campo apresentaram diminuições ano a ano, o que provavelmente está atrelado ao fechamento das escolas em áreas rurais. A situação se inverte na análise dos dados das matrículas de alunos com NEE que vivem e estudam no campo, com aumentos sucessivos no período.

Além disso, os dados de matrícula dos alunos com NEE que vivem no campo e estudam na cidade apontaram que o percentual é maior que daqueles que vivem e estudam no campo. Dando continuidade ao estudo de Caiado e Meletti (2011), apresenta-se a Tabela 2, com os dados do último censo escolar da educação básica.

Tabela 2: Matrículas de alunos com necessidades educacionais especiais por localização da residência e da escola no Brasil no ano de 2012

\begin{tabular}{lllllllllll}
\hline & \multicolumn{3}{l}{ Vive no campo e estuda no campo } & \multicolumn{4}{c}{ Vive no campo e estuda na cidade } \\
\cline { 2 - 9 } Ano & Total & $\begin{array}{l}\text { Possui } \\
\text { NEE }\end{array}$ & $\begin{array}{l}\text { Não possui } \\
\text { NEE }\end{array}$ & $\%$ & Total & $\begin{array}{l}\text { Possui } \\
\text { NEE }\end{array}$ & $\begin{array}{l}\text { Não possui } \\
\text { NEE }\end{array}$ & $\%$ \\
\hline 2012 & 5.746 .320 & 89.047 & 2 & 5.657 .273 & 98 & 4.097 .629 & 98.677 & 2 & 3.998 .952 & 98 \\
\hline
\end{tabular}

Fonte: Elaboração própria com base nos microdados do Inep (Brasil, 2012b). 
Ao cotejar esses dados com o estudo anterior (Caiado, Meletti, 2011), verificase que a tendência continua, com redução nas matrículas de alunos que vivem e estudam no campo e com o aumento nas matrículas de alunos que vivem no campo e estudam na cidade.

Com relação às matrículas de alunos com NEE que vivem no campo, percebe-se que a maioria precisa se deslocar até a cidade em busca de escolarização. O deslocamento dos alunos para a cidade nos leva a discutir várias questões importantes, dentre elas as condições de transporte escolar, enquanto condições dos veículos, das estradas, dos cuidados com as crianças durante os trajetos. Pode-se afirmar que o transporte escolar em áreas rurais é um sério problema para o acesso escolar, situação que se agrava muito para o aluno que necessita de um transporte escolar adaptado (Caiado; Gonçalves, 2014).

A partir deste panorama da educação básica presente no campo, o próximo passo é verificar a situação das pessoas com necessidades educacionais especiais que vivem e estudam no campo, segundo a localização das escolas: em assentamentos, terras indígenas, áreas remanescentes de quilombos e outras áreas rurais.

\section{Interface da educação especial na educação do campo: escolas em assentamentos, terras indígenas $\mathrm{e}$ áreas remanescentes de quilombos}

Atualmente a interface entre a educação especial na educação do campo consta em documentos e legislação específica do campo e da educação especial'. Para estudarmos essa interface, na dimensão das matrículas de alunos em escolas do campo, utilizaremos os dados dos indicadores educacionais.

Inicialmente, apresentamos as matrículas de alunos com NEE, que vivem no campo segundo a localização diferenciada da escola no Brasil, conforme ilustrado na Figura 2.

Resolução $n^{\circ}$ 2/2008 (Brasil, 2008a), Política Nacional de Educação Especial na Perspectiva da Educação Inclusiva (Brasil, 2008b). 
Figura 2: Matrículas de alunos com NEE segundo a localização diferenciada da escola no Brasil no período de 2008 a 2012

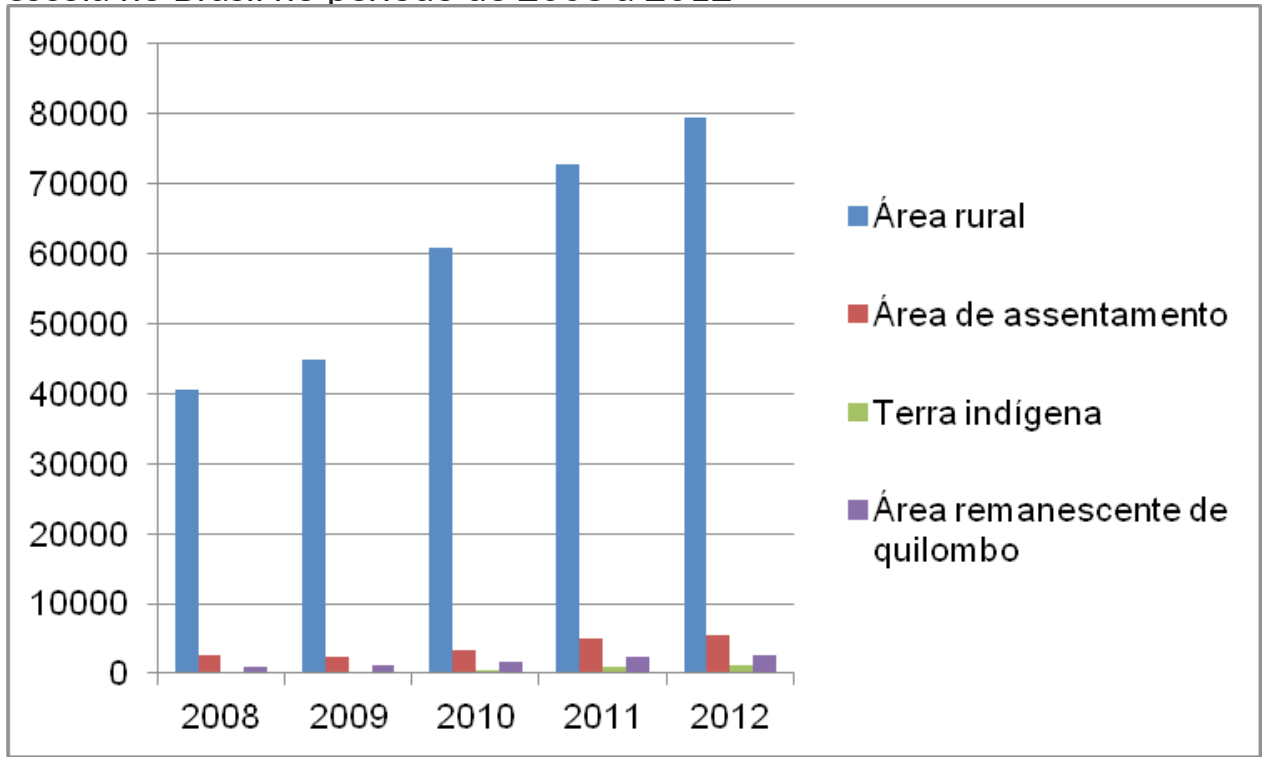

Fonte: Elaboração própria com base nos microdados do Inep (Brasil, 2008c; 2009a; 2010; 2011a; 2012b).

Baseando-se nos microdados do censo escolar (Brasil, 2008c; 2009a; 2010; 2011a; 2012b), em média, 1,7\% do total das matrículas da educação básica no Brasil corresponde a alunos com NEE.

Ao analisarmos cada área específica do campo, constata-se que a maior concentração das matrículas de alunos com NEE que vivem e estudam no campo está em áreas rurais, seguida, respectivamente, pela área de assentamento, terra indígena e área remanescente de quilombo.

As matrículas de alunos com NEE em área de assentamento representam 5,7\% do total de alunos com NEE que vivem e estudam no campo. Ao analisarmos o período de 2008 a 2012, percebe-se um aumento expressivo (116,6\%) no número de matrículas de alunos com NEE em escolas de assentamento.

Esses dados, contudo, não alteram a realidade apresentada por Di Pierro e Andrade (2009) sobre os assentamentos no estado de São Paulo quando mostram que a maioria dos alunos da educação básica que vive em área rural estuda em escolas urbanas. Tal fato,

[...] não só contraria a legislação e normas vigentes (que asseguram a crianças e adolescentes o estudo próximo à residência, em escolas com organização adequada, currículo relevante e práticas pedagógicas significativas), como entra em contradição 
com os projetos de formação humana das novas gerações e as aspirações de mudança nas relações político-econômicas, socioculturais e ambientais dos movimentos sociais do campo. Também inviabiliza a participação das famílias assentadas na gestão escolar, seja porque as escolas rurais têm pouca autonomia ou porque, em virtude da distância, as famílias não conseguem participar da gestão das escolas urbanas. (Di Pierro; Andrade, 2009, p. 255)

No caso das matrículas de alunos com NEE em terras indígenas eáreas remanescentes de quilombo, houve também um aumento no período. Este acréscimo, possivelmente, pode estar associado às conquistas legais que os povos indígenas e quilombolas tiveram nas políticas nacionais, as quais, hoje, garantem o reconhecimento cultural desses povos e escolas diferenciadas dentro de seus territórios (Brasil, 1988; 1996; 2012a).

Cabe destacar, porém, que esse número de matrículas deve aumentar ainda mais nos próximos anos, pois o acesso às políticas públicas, especificamente à educação, para os alunos indígenas e quilombolas com deficiência tornou-se reivindicação desses povos. Os indígenas, por exemplo, no IX Encontro sobre Leitura e Escrita em Sociedades Indígenas (IX ELESI), que teve por objetivo discutir temáticas atuais e prioritárias para as escolas e comunidades indígenas, produziram uma carta com várias propostas, dentre elas a solicitação de direitos aos índios com deficiência, ou seja:

Considerando a realidade dos Povos Indígenas e o avanço no domínio de suas línguas, considerando em suas necessidades aqueles que são portadores de necessidades especiais, sugerimos que sejam possibilitados os seguintes direitos aos Portadores Nacionais Indígenas de Necessidades Especiais PNE's:

- Acessibilidade à Educação Escolar Indígena para as crianças, jovens e adultos portadores de necessidades especiais;

- Possibilitar a formação escolar regular e profissionalizante para os PNE's indígenas;

- Facilitar o acesso às Políticas Públicas do país aos PNE's indígenas como forma de garantir a qualidade de vida destes;

- Promover a formação específica para os professores/profissionais que atuem na Educação Escolar Indígena com PNE's;

- Garantir a aposentadoria dos PNE's indígenas;

- Possibilitar/Garantir a acessibilidade aos Programas Federais, Estaduais e Municipais de saúde, educação, moradia, trabalho e lazer aos PNE's indígenas; 
- Criar espaços para discussão dos povos indígenas sobre o acesso e a permanência do indígena com deficiência;

- Formação de professores para o atendimento às crianças especiais mantendo o suporte necessário.

Com relação às matrículas nas áreas remanescentes de quilombos, estas tiveram acréscimo significativo $(159,1 \%)$ no período analisado (2008 a 2012). Apesar desse aumento expressivo, Mantovani (2013, p. 17) nos alerta que para efetivar a interface da educação especial na educação escolar quilombola "[...] há um longo caminho para ser trilhado em que o movimento social tanto das pessoas com deficiências quanto das comunidades quilombolas do Brasil precisarão lutar para efetivação dos direitos conquistados".

De modo geral, os dados apontam uma tendência de ampliação nas matrículas de alunos com NEE no campo. Esse aumento possivelmente está associado às ações de programas de governo, a partir do Plano de Desenvolvimento da Educação (Brasil, 2007a) e da Política Nacional de Educação Especial na Perspectiva da Educação Inclusiva (Brasil, 2008b). Nessa direção, destaca-se o Plano Viver sem Limite (Brasil, 2011b) em que há várias ações que visam responder ao compromisso assumido pelo Brasil ratificando, como emenda constitucional, a Convenção sobre os Direitos das Pessoas com Deficiência ${ }^{8}$. Esse Plano contempla ações nas áreas da educação, inclusão social, acessibilidade e saúde. Visando o acesso à educação básica, os investimentos estão destinados a: recursos e serviços de apoio à educação básica, como a implantação de Salas de Recursos Multifuncionais (SRM), a promoção de acessibilidade arquitetônica nas escolas, a formação de professores para realização do atendimento educacional especializado (AEE), a aquisição de ônibus escolares acessíveis e a implementação do Programa BPC na Escola, que "é uma ação interministerial voltada a crianças e adolescentes com deficiência que recebem o BPC. Em 2007, o programa constatou que cerca de $70 \%$ delas estavam fora da escola" (Brasil, 2013).

Percebe-se que a situação escolar dos beneficiários em nosso país ainda é um desafio. Desse modo, pretende-se analisar a situação escolar desses beneficiários segundo a moradia.

\section{Situação escolar do beneficiário segundo a moradia}

Desde a Constituição de 1988 os idosos e as pessoas com deficiência têm direito

${ }^{8}$ Decreto $n^{\circ}$ 6.949, de 25 de agosto de 2009 (Brasil, 2009b). 
a receber um salário mínimo ao comprovarem não possuir meios de prover a própria manutenção - direito regulamentado como Benefício de Prestação Continuada (BPC), em 1993, instituído pela Constituição Federal de 1988 e regulamentado pela Lei Orgânica da Assistência Social (LOAS), Lei nº 8.742 (Brasil, 1993), de 7 de dezembro de 1993; pelas leis $n^{\circ} 12.435$ (Brasil, 2011c), de 6 de julho de 2011, e $n^{\circ}$ 12.470 (Brasil, 2011d), de 31 de agosto de 2011, que alteram dispositivos da LOAS, e pelos decretos $n^{\circ} 6.214$ (Brasil, 2007b), de 26 de setembro de 2007, e $n^{\circ} 6.564$ (Brasil, 2008d), de 12 de setembro de 2008.

Esse benefício integra o Sistema Único da Assistência Social (SUAS), pago pelo Governo Federal, cuja operacionalização de reconhecimento do direito é do Instituto Nacional do Seguro Social (INSS). Assegurado por lei, permite o acesso de idosos e pessoas com deficiência à proteção social básica com dois campos de atuação: os serviços e os benefícios de caráter pecuniário.

Em 2007, foi realizado o primeiro cruzamento entre bases de dados do Ministério da Previdência Social e do Ministério da Educação. Esse estudo mostrou que dentre os 340.536 beneficiários do BPC, pessoas com deficiência na faixa etária de zero a dezoito anos, 100.574 (29,53\%), estavam matriculados em escolas, enquanto 239.962 (70,47\%) não tinham registros no sistema regular de ensino. Esse quadro provocou a criação de um Programa de Acompanhamento e Monitoramento do Acesso e Permanência na Escola da Pessoa com Deficiência Beneficiária do BPC, o Programa BPC na Escola (Brasil, 2007c). O Programa envolve o Ministério do Desenvolvimento Social e Combate à Fome (MDS), o Ministério da Educação (MEC), o Ministério da Saúde (MS) e a Secretaria de Direitos Humanos da Presidência da República (SEH/PR) e tem como objetivo:

[...] promover a elevação da qualidade de vida e dignidade das pessoas com deficiência beneficiárias do BPC, preferencialmente de 0 a 18 anos de idade, garantindo-lhes acesso e permanência na escola, por meio de ações articuladas da área de saúde, educação, assistência social e direitos humanos. (Brasil, 2007c)

O Programa BPC na Escola integra o Plano de Desenvolvimento da Educação (PDE) ${ }^{9}$ e o Plano Viver sem Limite (Brasil, 2011b). Este assegura verbas aos municípios e estados que aderirem ao Programa.

Esse programa nos chamou a atenção, pois seu foco ${ }^{10}$ está em um dos segmentos da população mais abandonado pelas políticas públicas em nosso país. Os beneficiários com deficiência recebem mensalmente 1 (um) salário mínimo desde que comprovem não possuir meios de prover sua subsistência, dada sua incapacidade para a vida independente e para o trabalho, e viva com uma família, cuja renda mensal per

\footnotetext{
9 Sobre o Plano de Desenvolvimento da Educação (PDE), ver Saviani (2009).

10 Não é objeto deste estudo discutir a tensão entre políticas focais ou universais. Nossa compreensão é pela luta por políticas universais. Porém, há segmentos que não podem mais esperar.
} 
capita seja inferior a 1/4 (um quarto) do salário mínimo.

Sim, temos no país famílias que não podem comprovar uma renda per capita mensal superior a um quarto de salário mínimo ${ }^{11}$. Em 2010 havia 3,32 milhões de beneficiários, sendo 1,59 milhões de idosos e 1,73 milhões de pessoas com deficiência ${ }^{12}$.

Como forma de ilustrar melhor essa situação, apresentaremos os dados do BPC na Escola que foram extraídos dos relatórios ${ }^{13}$ elaborados a partir das visitas domiciliares aos beneficiários com deficiência, com idade entre 0 e 18 anos, cujo objetivo foi identificar as barreiras para acesso e permanência na escola. As visitas domiciliares foram realizadas no período de janeiro de 2009 a maio de 2010, no Distrito Federal e nos municípios que aderiram ao Programa BPC na Escola em 2008.

Com o intuito de verificar a situação escolar dos beneficiários segundo a área de moradia (urbana; rural), apresenta-se a Tabela 3.

Tabela 3: Relatórios BPC - Beneficiários na escola e fora da escola por área de moradia (5 regiões)

\begin{tabular}{|c|c|c|c|c|c|c|}
\hline \multirow[b]{2}{*}{ Regiões } & \multicolumn{3}{|c|}{$\begin{array}{l}\text { Beneficiário que vive na zona } \\
\text { urbana }\end{array}$} & \multicolumn{3}{|c|}{ Beneficiário que vive na zona rural } \\
\hline & $\begin{array}{l}\text { Frequenta } \\
\text { a escola }{ }^{16}\end{array}$ & $\begin{array}{l}\text { Já } \\
\text { frequentou } \\
\text { a escola e } \\
\text { agora não } \\
\text { frequenta }\end{array}$ & $\begin{array}{l}\text { Nunca } \\
\text { frequentou } \\
\text { a escola }\end{array}$ & $\begin{array}{l}\text { Frequenta } \\
\text { a escola }\end{array}$ & $\begin{array}{l}\text { Já frequentou } \\
\text { a escola e } \\
\text { agora não } \\
\text { frequenta }\end{array}$ & $\begin{array}{l}\text { Nunca } \\
\text { frequentou } \\
\text { a escola }\end{array}$ \\
\hline Norte & 7200 & 1693 & 2076 & 1954 & 444 & 881 \\
\hline Nordeste & 22750 & 5992 & 7687 & 10072 & 3285 & 5782 \\
\hline Centro Oeste & 6516 & 1011 & 713 & 510 & 110 & 119 \\
\hline Sudeste & 29180 & 4566 & 4321 & 3086 & 574 & 677 \\
\hline Sul & 8094 & 939 & 765 & 1670 & 192 & 187 \\
\hline Brasil & 73740 & 14201 & 15562 & 17292 & 4605 & 7646 \\
\hline
\end{tabular}

O primeiro dado a se comentar é que em nosso país, no ano de 2010 , a maior parte dos beneficiários frequentava a escola $(68,42 \%)$, aspecto positivo, pois no ano de 2007 foi identificado no país que somente $21 \%$ dos beneficiários do BPC com

\footnotetext{
11 Salário mínimo em janeiro de 2015 é de $\mathrm{R} \$ 788,00$ (setecentos e oitenta e oito reais).

12 Disponível em: <http://aplicacoes.mds.gov.br/sagi/PainelBPC/>. Acesso em: 11 fev. 2014.

13 Relatórios divulgados no site: <www.bpcnaescola.mec.gov>. Acesso em: 13 jan. 2014.

16 Período da coleta dos dados: janeiro 2009 a maio de 2010.
} 
deficiência, na faixa etária entre 0 e 18 anos, estavam na escola (Brasil, 2013). Este aumento do acesso à escola, por parte dos beneficiários, deve estar relacionado à implementação do Programa BPC na Escola. Porém, é preciso salientar que atualmente ainda há $31,58 \%$ dos beneficiários (campo e cidade) fora da escola.

Embora no Brasil a maioria dos beneficiários que vivem em área urbana frequente a escola, verifica-se que $28,76 \%$ dos beneficiários de áreas urbanas já frequentaram a escola e não frequentam atualmente ou nunca frequentaram.

A situação escolar dos beneficiários que vivem no campo é ainda mais alarmante em nosso país, sendo que $41,47 \%$ dos beneficiários que vivem em área rural já frequentaram a escola e não frequentam atualmente ou nunca frequentaram. Este dado demonstra a dificuldade que se tem para implementar políticas públicas aos povos do campo e revela ainda a invisibilidade deles perante a sociedade.

Nas regiões Norte e Nordeste, verifica-se que, respectivamente, 35,75\% e 40,93\% dos beneficiários (da cidade e do campo) já frequentaram a escola e não frequentam atualmente ou nunca frequentaram. De acordo com os dados do IBGE de 2001 (Brasil, 2003), a região Norte tinha taxa de analfabetismo de $12,4 \%$ da população de 15 anos ou mais, sendo a situação da região Nordeste mais alarmante $(28,7 \%)$ na mesma faixa etária, um contingente de quase oito milhões de analfabetos, segundo a mesma fonte. O último censo demográfico (IBGE, 2010) mostra que houve pouca mudança nos índices dessas regiões, pois continuam com a maior taxa de analfabetismo do país (Nordeste 19,1\% e Norte 11,2\%), o que corresponde mais de $50 \%$ do total de analfabetos do país. Diante do exposto, percebe-se que o problema do acesso à escolarização nas regiões Norte e Nordeste não é uma dificuldade encontrada apenas pelos alunos com deficiência, mas também por muitos alunos da educação básica (Ferraro; Machado, 2002).

Em síntese, é a primeira vez na história da educação que se formula um Programa voltado à educação especial escolar para as pessoas com deficiência das camadas sociais mais desfavorecidas (Caiado et al., 2014). Com isso, são inúmeros os desafios para que esses alunos permaneçam nas escolas e nelas se apropriem do conhecimento escolar. Muitos alunos/beneficiários têm entrada tardia na escola e, portanto, significativa defasagem idade/série. Além disso, encontrarão graves barreiras sociais, que se concretizam em barreiras arquitetônicas, de atitudes e de comunicação e se colocam historicamente às pessoas com deficiência, que ainda convivem com ações assistencialistas. Daí a urgência e o compromisso de pesquisadores, professores e movimento social em acompanhar o Programa e dar subsídios para superação dos desafios, na luta pelo direito à escola. 


\section{Considerações finais}

Há no país uma cruel desigualdade social, que se desdobra nas desigualdades escolares. Conhecer essa realidade é ponto de partida para elaborarmos qualquer proposta de superação, seja com ações imediatas, seja para a construção de um novo projeto de sociedade, comprometido com a dignidade do homem, em que a educação não é um negócio, é criação, não é qualificação para o mercado, mas formação para a vida. A educação não é uma mercadoria (Mészàros, 2008).

Atualmente, um discurso sedutor envolve a área da educação e da educação especial proclamando a inclusão das diferenças, inclusive dos alunos com deficiência. Em nome dos direitos humanos, o Banco Mundial (OMS, 2011, p. 10) tem se ocupado com a condição da deficiência e tem promovido várias pesquisas para conhecer o custo dos investimentos sociais na área. Com a explicação circular de que a pobreza é causa e efeito, afirma que "a deficiência é uma questão de desenvolvimento, devido à sua relação bidirecional com a pobreza: a deficiência pode aumentar o risco de pobreza, e esta pode aumentar o risco de deficiência". Com inúmeras referências aos custos e investimentos, em diferentes áreas como saúde, educação, trabalho e tecnologias, conclui que "muitos desses custos devem-se a ambientes inacessíveis e poderiam ser menores em um cenário mais inclusivo" (OMS, 2011, p. 44). Na defesa da escola inclusiva, apoia-se nas razões elencadas pela Organização das Nações Unidas para a educação, a ciência e a cultura (UNESCO), com argumentos na área educacional, social e econômica:

Educacional: O requisito para as escolas inclusivas educarem todas as crianças juntas é que as escolas desenvolvam métodos de ensino que respondam às diferenças individuais, para o benefício de todas as crianças.

Social: Escolas inclusivas podem mudar as atitudes daqueles que são, de certa forma 'diferentes', educando todas as crianças juntas. Isto ajudará a criar uma sociedade justa sem discriminação.

Econômica: Estabelecer e manter escolas para educar todas as crianças juntas é mais barato do que criar um sistema complexo de diferentes tipos de escolas especializadas para diferentes grupos de crianças. (OMS, 2011, p. 218)

O projeto de educação que compreende a educação escolar como formação humana defende a escola como um direito e não porque os investimentos serão maiores se as pessoas com deficiência permanecerem em casa ou em instituições especializadas.

Para um aluno chegar à escola, nela permanecer e aprender precisam ser garantidas inúmeras e complexas condições. Principalmente quando é um aluno com deficiência 
em que as barreiras sociais de toda ordem impedem a convivência social e seu desenvolvimento. Com isso, conhecer a realidade é fundamental para a formulação e implementação de propostas que promovam a superação dos desafios.

Nessa direção, faz-se necessário conhecer a realidade diferenciada que existe nas escolas do campo, dentre elas: escolas de assentamentos, terras indígenas e de áreas remanescentes de quilombos. Necessário, também, o diálogo com os movimentos sociais para conhecer as vivências que trazem e o projeto de educação que debatem, para nos colocarmos juntos na garantia do direito à educação escolar também para os alunos com deficiência.

Por fim, a intenção deste estudo foi mostrar que há pessoas com deficiência nesses lugares e que precisamos pesquisar sobre as condições reais de vida e de contexto escolar nas quais esses sujeitos se encontram. Assim, destacamos que campo e cidade compõem um único projeto político de sociedade e educação, projeto hoje caracterizado pela desigualdade social e escolar.

\section{Referências}

BRASIL. Constituição (1988). Constituição da República Federativa do Brasil. Brasília, DF: Senado, 1988.

Lei $n^{\circ}$ 8.742, de 7 de dezembro de 1993. Dispõe sobre a organização da Assistência Social e dá outras providências. Lex. Brasília, DF, 1993. Disponível em: <http://www4.planalto.gov.br/legislacao>. Acesso em: 18 jan. 2014.

Lei $n^{\circ} .9 .394$, de 20 de dezembro de 1996. Estabelece as diretrizes e bases da educação nacional. Diário Oficial da República Federativa do Brasil, Brasília, DF, n. 248, 23 dez. 1996.

Mapa do analfabetismo no Brasil. Brasília, DF: MEC/INEP, 2003. Disponível em: $\quad$ http://www.publicacoes.inep.gov.br/arquivos/\%7B3D805070-D9D042DC-97AC-5524E567FC02\%7D_MAPA\%20DO\%20ANALFABETISMO\%20 NO\%20BRASIL.pdf >. Acesso em: 14 fev. 2014.

. Portaria Normativa Interministerial $n^{\circ} 18$, de 24 de abril de 2007. Cria o Programa de Acompanhamento e Monitoramento do Acesso e Permanência na Escola das Pessoas com Deficiência Beneficiárias do Benefício de Prestação Continuada da Assistência Social. Brasília, DF, 2007a. Disponível em: <http://www.mec.gov.br>. Acesso em: 18 jan. 2014. 
. Decreto $n^{\circ}$ 6.214, de 26 de setembro de 2007b. Regulamenta o Benefício de Prestação Continuada da assistência social devido à pessoa com deficiência e ao idoso de que trata a Lei n o 8.742, de 7 de dezembro de 1993, e a Lei n o 10.741, de 1 o de outubro de 2003, acresce parágrafo ao art. 162 do Decreto n o 3.048, de 6 de maio de 1999, e dá outras providências. Diário Oficial da União, Brasília, DF, 2007b. Disponível em: <http://www.planalto.gov.br/ccivil_03/_ato20072010/2007/decreto/d6214.htm>. Acesso em: 14 jan.2014.

BPC na Escola. Documento Orientador. Brasília, DF, 2007c. Disponível em: <portal.mec.gov.br>. Acesso em: 13 jan. 2014.

Ministério da Educação. Conselho Nacional de Educação. Câmara de Educação Básica. Resolução ${ }^{\circ} 2$, de 28 de abril de 2008a. Estabelece diretrizes complementares, normas e princípios para o desenvolvimento de políticas públicas de atendimento da Educação Básica do Campo. Brasília, DF, 2008a. Disponível em: <http://www.mec.gov.br>. Acesso em: 11 jan. 2013.

Ministério da Educação. Política Nacional de Educação Especial na Perspectiva da Educação Inclusiva. Brasília, DF: MEC, 2008b. Disponível em: <http://www.mec.gov.br>. Acesso em: 13 mar. 2013.

Ministério da Educação. Instituto Nacional de Estudos e Pesquisas Educacionais Anísio Teixeira - INEP. Censo Escolar da Educação Básica 2008. Brasília, DF, 2008c. Disponível em: <http://www.inep.gov.br/basica/ levantamentos/microdados.asp>. Acesso em: 07 dez. 2013.

Decreto $n^{\circ}$ 6.564, de 12 de setembro de 2008d. Altera o Regulamento do Benefício de Prestação Continuada, aprovado pelo Decreto no 6.214, de 26 de setembro de 2007, e dá outras providências. Diário Oficial da União, Brasília, DF, 2008d. Disponível em: <http://www.planalto.gov.br/ccivil_03/_ato20072010/2008/Decreto/D6564.htm>. Acesso em: 14 jan.2014.

Ministério da Educação. Instituto Nacional de Estudos e Pesquisas Educacionais Anísio Teixeira - INEP. Censo Escolar da Educação Básica 2009. Brasília, DF, 2009a. Disponível em: <http://www.inep.gov.br/basica/ levantamentos/microdados.asp>. Acesso em: 08 dez. 2013.

. Decreto $\mathrm{n}^{\circ}$ 6.949, de 25 de agosto de 2009. Promulga a Convenção Internacional sobre os Direitos das Pessoas com Deficiência e seu Protocolo Facultativo, assinados em Nova York, em 30 de março de 2007. Lex, Brasília, DF, 2009b. Disponível em: <http://www4.planalto.gov.br/legislacao>. Acesso em: 18 jan. 2014. 
Ministério da Educação. Instituto Nacional de Estudos e Pesquisas Educacionais Anísio Teixeira - INEP. Censo Escolar da Educação Básica - 2010. Brasília, DF, 2010. Disponível em: <http://www.inep.gov.br/basica/levantamentos/ microdados.asp>. Acesso em: 08 dez. 2013.

Ministério da Educação. Instituto Nacional de Estudos e Pesquisas Educacionais Anísio Teixeira - INEP. Censo Escolar da Educação Básica 2011. Brasília, DF, 2011a. Disponível em: <http://www.inep.gov.br/basica/ levantamentos/microdados.asp> Acesso em: 09 dez. 2013.

Decreto $n^{\circ} 7.612$, de 17 de novembro de 2011. Institui o Plano Nacional dos Direitos da Pessoa com Deficiência - Plano Viver sem Limite. Lex, Brasília, DF, 2011b. Disponível em: <http://www.planalto.gov.br/ccivil_03/_Ato20112014/2011/Decreto/D7612.htm>. Acesso em: 03 fev. 2014.

Lei $n^{\circ}$ 12.435, de 6 de julho de 2011c. Altera a Lei no 8.742, de 7 de dezembro de 1993, que dispõe sobre a organização da Assistência Social. Brasília, DF, 2011c. Disponível em: <http://www.planalto.gov.br/ccivil_03/_Ato20112014/2011/Lei/L12435.htm>.Acesso em:13 fev. 2014.

. Lei $n^{\circ}$ 12.470. Brasília, DF, 2011d. Disponível em: <http://www.planalto. gov.br/ccivil_03/_ato2011-2014/2011/lei/l12470.htm>. Acesso em: 15 fev. 2014.

Resolução $n^{\circ}$ 8, de 20 de dezembro de 2012. Define Diretrizes Curriculares Nacionais para a Educação Escolar Quilombola na Educação Básica. Brasília, DF, 2012a. Disponível em: <http://www.seppir.gov.br/arquivos-pdf/diretrizescurriculares >. Acesso em: 12 fev. 2014.

Ministério da Educação. Instituto Nacional de Estudos e Pesquisas Educacionais Anísio Teixeira - INEP. Censo Escolar da Educação Básica 2012. Brasília, DF, 2012b. Disponível em: <http://www.inep.gov.br/basica/ levantamentos/microdados.asp>. Acesso em: 10 dez. 2013.

. Ministério da Educação. Secretaria de Educação Continuada, Alfabetização, Diversidade e Inclusão. Diretoria de Políticas de Educação Especial. Nota Técnica ${ }^{\circ}$ 13/2013, de 08 de fevereiro de 2013. Brasília, DF, 2013. Disponível em: <portal. mec.gov.br>. Acesso em: 11 fev. 2014.

Lei $n^{\circ}$ 13.005, de 25 de junho de 2014. Aprova o Plano Nacional de Educação, e outras providências. Lex. Brasília, DF, 2014a. Disponível em: <http:// www.planalto.gov.br>. Acesso em: 13 ago. 2014. 
. Lei 12.960, de 27 de março de 2014. Altera a Lei $n^{\circ}$ 9.394, de 20 de dezembro de 1996, que estabelece as diretrizes e bases da educação nacional, para fazer constar a exigência de manifestação de órgão normativo do sistema de ensino para o fechamento de escolas do campo, indígenas e quilombolas. Lex. Brasília, DF, 2014b. Disponível em: <http://presrepublica.jusbrasil.com.br/ legislacao/114664351/lei-12960-14>. Acesso em: 1 abr. 2014.

BRUNO, Marilda Moraes Garcia. Mapeamento de deficiências na população indígena da Região da Grande Dourados, MS: um estudo sobre os impactos e as possíveis implicações para a inclusão educacional. Universidade Federal da Grande Dourados: Departamento de Educação. Projeto de Pesquisa financiado pela CAPES, 2009.

CAIADO, Katia Regina Moreno; MELETTI, Silvia Marcia Ferreira. Educação especial na educação do campo: 20 anos de silêncio no GT 15. Revista Brasileira de Educação Especial, Marília, UNESP, v. 17, p. 93-104, maio-ago. 2011.

CAIADO, Katia Regina Moreno; GONCALVES, Taísa Grasiela Gomes Liduenha. Educação Especial em escolas do campo: análise de um município do Estado de São Paulo. Revista HISTEDBR On-line, v. 13, p. 179-193, maio 2013.

CAIADO, Katia Regina Moreno; GONÇALVES, Taísa Grasiela Gomes Liduenha. O transporte escolar público para os alunos do campo com necessidades educacionais especiais. Revista Teoria e Prática da Educação, Maringá, Universidade Federal do Maringá. v. 17, p. 119-130, maio-ago. 2014.

CAIADO, Katia Regina Moreno et al. Deficiência e desigualdade social: o recente caminho para a escola. Cadernos Cedes, Campinas, Unicamp, v. 34, n. 93, p. 241260, maio-ago. 2014.

DI PIERRO, Maria Clara; ANDRADE, Marcia Regina. Escolarização em assentamentos no estado de São Paulo: uma análise da Pesquisa Nacional de Educação na Reforma Agrária 2004. Revista Brasileira de Educação, Rio de Janeiro, ANPED, v. 14, n. 41, p. 246-257, maio-ago. 2009.

FERRARO, Alceu Ravanello. Quantidade e qualidade na pesquisa em educação, na perspectiva da dialética marxista. Pro-Posições, Campinas, Unicamp, v. 23, n. 1, p. 129-146, jan.-abr. 2012.

FERRARO, Alceu Ravanello; MACHADO, Nádie Christina Ferreira. Da universalização do acesso à escola no Brasil. Educação \& Sociedade, Campinas, Unicamp, v. 23, n. 79, p. 213-241, ago. 2002.

GRAMSCI, Antonio. Concepção Dialética da História. 4. ed. Rio de Janeiro: Civilização Brasileira, 1981. 
HAGE, Salomão Antônio Mufarrej. A multissérie em pauta: para transgredir o paradigma seriado nas escolas do campo. In: MUNARIM, Antônio et al. (org.). Educação do campo: políticas públicas, territorialidades e práticas pedagógicas. Florianópolis: Editora Insular Ltda, 2011. p. 123-144.

IBGE. Instituto Brasileiro de Geografia e Estatística. Censo Demográfico 2010. Brasília, DF, 2010. Disponível em: <http://www.ibge.gov.br/home/estatistica/ populacao/censo2010/indicadores_sociais_ municipais/ tabelas_pdf/tab5.pdf $>$. Acesso em: 14 fev. 2014.

IBGE. SIDRA. Sistema IBGE de Recuperação Automática. Brasília, 2012. Disponível em: <http://www.sidra.ibge.gov.br>. Acesso em: 26 jan. 2014.

MANTOVANI, Juliana Vechetti. Educação escolar Quilombola e educação especial: alguns avanços para a construção da interface. In: Seminário nacional de estudos e pesquisas sobre educação do campo e IV Jornada de educação especial no campo, 2, 2013, São Carlos, Anais... São Carlos, 2013. Disponível em: <http://www.gepec. ufscar.br/>. Acesso em: 31 mar. 2014.

MÉSZÀrOS, István. A educação para além do capital. 2. ed. São Paulo: Boitempo, 2008.

MUNARIM, Antonio. Educação do Campo no Cenário das Políticas Públicas na Primeira Década do Século XXI. Em Aberto, Brasília, INEP, v. 24, p. 51-63, abr. 2011.

OLIVEIRA, Ivanilde Apoluceno et al. Educação em classes multisseriadas na Amazônia: singularidade, diversidade e heterogeneidade. Belém: EDUEPA, 2011.

OMS. ORGANIZAÇÃO MUNDIAL DA SAÚDE. Relatório mundial sobre a deficiência, World Health Organization, The World Bank. Trad. Lexicus Serviços Lingüísticos. São Paulo: Secretaria de Estado dos Direitos da Pessoa com Deficiência de São Paulo (SEDPcD), 2012.

PINTO, José Marcelino de Rezende. Fundos públicos. In: CALDART, Roseli Salete et al. (org.). Dicionário do Campo. Rio de Janeiro: Expressão Popular, 2012.

ROMANELLI, Otaíza. História da Educação no Brasil (1930-1973). 21. ed. Petrópolis: Vozes, 1998.

SÁ, Michele Aparecida de. Criança indígena com deficiência na escola indígena: Limites e possibilidades. In: Seminário nacional de estudos e pesquisas sobre educação do campo e IV Jornada de educação especial no campo, 2, 2013, São Carlos, Anais..., São Carlos, 2013. Disponível em: <http://www.gepec.ufscar.br/>. Acesso em: 31 mar. 2014. 
VENDRAMINI, Célia Regina. Educação e Trabalho: Reflexões em torno dos movimentos sociais do campo. Educação \& Sociedade, Campinas, Unicamp, v. 27, p. 121-135, maio-ago. 2007.

\section{Recebido em julho de 2015 \\ Aprovado em outubro de 2015}

Katia Regina Moreno Caiado é doutora em Educação pela Universidade de São Paulo (USP), professora da Universidade Federal de São Carlos (UFSCar) e também atua no Programa de Pós-Graduação em Educação Especial. E-mail: caiado.katia@gmail.com

Taísa Grasiela Gomes Liduenha Gonçalves é doutora em Educação Especial pela Universidade Federal de São Carlos (UFSCar) e docente do Programa de Pós-Graduação em Metodologias para o Ensino de Linguagens e suas Tecnologias na Universidade Norte do Paraná (UNOPAR). E-mail: taisaliduenha@gmail.com

Michele Aparecida de Sá é doutora em Educação Especial pela Universidade Federal de São Carlos (UFSCar) e professora no Centro Universitário Metodista Izabela Hendrix (IMIH). E-mail: micheledesa20@hotmail.com 